\title{
Effects of Nitric Oxide Annealing of Thermally Grown Silicon Dioxide Characteristics
}

Z.-Q. Yao, Student Member, IEEE, H. B. Harrison, S. Dimitrijev, Member, IEEE, and Y. T. Yeow, Senior Member, IEEE

\begin{abstract}
The effects of nitric oxide (NO) annealing on conventional thermal oxides are reported in this letter. The oxide thickness increase, resulting from NO annealing, is found to be only a few angstroms $(<0.5 \mathrm{~nm})$ and independent on the initial oxide thickness. Furthermore, both the electrical and physical characteristics are improved. This technique is expected to achieve sub-5 $\mathrm{nm}$ high quality ultrathin dielectric films for the applications in EEPROM's and ULSI.
\end{abstract}

\section{INTRODUCTION}

V ERY thin dielectric films are needed for the gate dielectrics for scaled MOSFET's, EPROM's, and EEPROM's. For these devices, dielectric films should have low leakage characteristics and high dielectric strength. For gate oxide thickness less than $5 \mathrm{~nm}$, the properties of conventional $\mathrm{SiO}_{2}$ in these applications are not acceptable [1]-[3]. Currently, the search for an alternative gate dielectric film points towards the incorporation of nitrogen in the oxides. Thermal nitridation in ammonia $\left(\mathrm{NH}_{3}\right)$ and in a nitrous oxide $\left(\mathrm{N}_{2} \mathrm{O}\right)$ ambient have recently been reported to lead to dielectrics of superior properties over conventional thermal oxides due to the incorporation of nitrogen in the vicinity of the dielectric-silicon substrate interface region [4]-[10]. However, the dielectric films which were nitrided in $\mathrm{NH}_{3}$ showed large amounts of electron trapping and mobility degradation due to the incorporation of hydrogen atoms and "heavy" nitridation [4], [7], [8], whereas $\mathrm{N}_{2} \mathrm{O}$-oxynitridation showed insufficient nitrogen in the dielectric films to prevent boron penetration from the boron-doped polysilicon gates [11]-[13]. We have suggested the use of nitric oxide (NO) as a dielectric growth ambient to obtain high quality ultrathin dielectric films [14]-[16]. However, since the growth in NO ambient is self-limiting, due to the creation of strong $\mathrm{Si}-\mathrm{N}$ bonds at the dielectric-silicon interface region, it is very difficult to obtain a dielectric film which is thicker than about $3.5 \mathrm{~nm}$ for reasonable growth times. In order to obtain high quality dielectric films of desired thicknesses, a two-step process may be necessary: an initial oxide grown in pure oxygen, and then annealed in an NO ambient. In this letter, we report the effects of NO anneal on conventional oxides of less than $5 \mathrm{~nm}$.

Manuscript received January 3, 1995; revised April 25, 1995.

Z.-Q. Yao is with AWA Microelectronics Pty Ltd. NSW 2140, Sydney, Australia.

H. B. Harrison and S. Dimitrijev are with the School of Microelectronic Engineering, Griffith University, Nathan, QLD 4111, Australia.

Y. T. Yeow is with the Department of Electrical and Computer Engineering, The University of Queensland, St. Lucia, QLD 4072, Australia.

IEEE Log Number 9413021.

\section{EXPERIMENTAL}

1.4-5.0 $\Omega \cdot \mathrm{cm} n$-type ( 100$)$ silicon wafers were cleaned using both a $\mathrm{H}_{2} \mathrm{SO}_{4} / \mathrm{H}_{2} \mathrm{O}_{2}$ solution and RCA cleaning process. The wafers were then washed in $1 \% \mathrm{HF}$ for $60 \mathrm{~s}$ immediately prior to dielectric film growth. The films were grown in an AG610 rapid thermal processing (RTP) unit. The initial oxides were grown in the RTP unit in an ultra-high purity oxygen ambient at $950^{\circ} \mathrm{C}$ for $30 \mathrm{~s}$. Then, the samples were annealed in a nitric oxide ambient at $1000^{\circ} \mathrm{C}$ and $1150^{\circ} \mathrm{C}$, both for $5 \mathrm{~min}$. These samples are referred to as ON1 and $\mathrm{ON} 2$, respectively. Other samples were grown at $1000^{\circ} \mathrm{C}$ for $25 \mathrm{~s}$ in $\mathrm{O}_{2}$ and then annealed in a nitric oxide ambient at $1150^{\circ} \mathrm{C}$ for 1 and $5 \mathrm{~min}$. The purity of the nitric oxide gas used throughout this experiment was $99.0 \%$ (chemical pure grade). The RTP chamber was purged with ultra high purity $\mathrm{N}_{2}$ prior to the introduction of $\mathrm{O}_{2}$ or NO. Aluminum gate MOS capacitors (area $=0.01 \mathrm{~cm}^{2}$ ) were fabricated to evaluate the electrical characteristics.

XPS measurements were carried out on a Perkin-Elmer PHI model 560 electron spectrometer with an Mg X-ray source to determine the nitrogen concentration and distribution throughout the dielectric film. Thicknesses of the dielectric films in this work, including the pure oxides, were measured using ellipsometry with three angles of incidence $\left(60^{\circ}, 65^{\circ}\right.$, and $70^{\circ}$ ). This method allows for the extraction of both the film thickness and the refractive index. The refractive index of those NO-grown or NO-annealed oxynitride is unknown, due to the incorporation of nitrogen. Moreover, the nitrogen distribution in the NO-annealed film is nonuniform inside the film. Thus, the single layer model for the calculation could result in inaccuracies, especially for such thin film. In this work, a two-layer model was used during the calculation, which necessitated at least two angles of incidence. We use three angles, and thus, three combinations, to get more accurate results. An HP4145B semiconductor parameter analyzer and an HP4284A LCR meter were used to obtain current-voltage $(\mathrm{J}-\mathrm{V})$, high frequency voltage-capacitance $(\mathrm{C}-\mathrm{V})$, and smallsignal conductance $(\mathrm{G}-\mathrm{V})$ characteristics of MOS capacitors before and after positive gate bias Fowler-Nordheim constantcurrent tunneling stress.

\section{RESUlts AND Discussion}

The thickness of the initial oxides of samples ON1 and ON2, grown in pure $\mathrm{O}_{2}$ ambient at $950^{\circ} \mathrm{C}$ for $30 \mathrm{~s}$, was 4.0 $\mathrm{nm}$. The overall dielectric thicknesses were $4.4 \mathrm{~nm}$ for both $1000^{\circ} \mathrm{C}$ and $1150^{\circ} \mathrm{C}$ anneal in NO, with the top layer of 3.2 $\mathrm{nm}$ with refractive index $n=1.49$ and the bottom layer of 


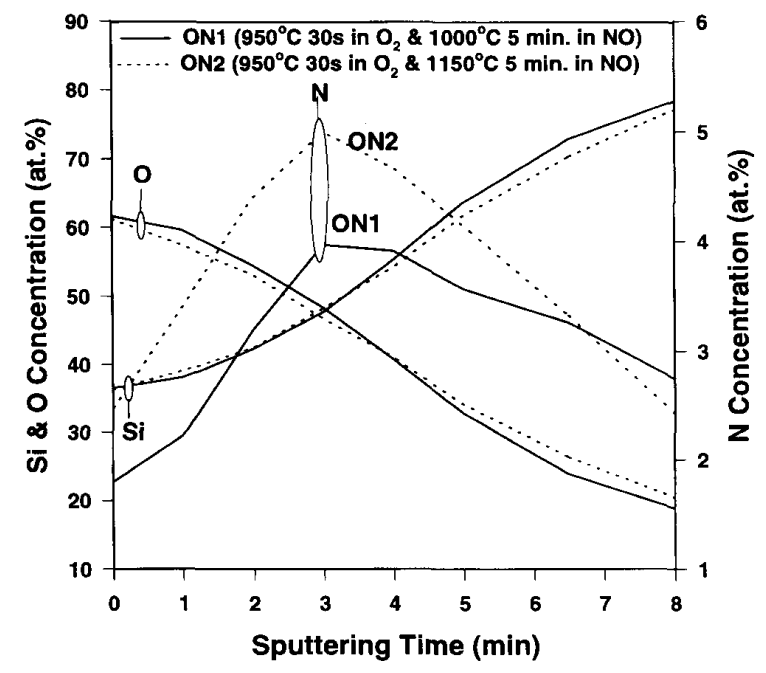

Fig. 1. XPS depth profiles for NO-annealed oxides ON1 (solid lines), which were annealed in $\mathrm{NO}$ at $1000^{\circ} \mathrm{C}$ for $5 \mathrm{~min}$., and $\mathrm{ON} 2$ samples (dashed lines) which were annealed in $\mathrm{NO}$ at $1150^{\circ} \mathrm{C}$ for $5 \mathrm{~min}$.

$1.2 \mathrm{~nm}$ with $n=1.56$ for $\mathrm{ON} 1$, and the top layer of $3.2 \mathrm{~nm}$ with refractive index $n=1.49$ and the bottom layer of 1.2 $\mathrm{nm}$ with $n=1.61$ for ON2. This result shows that the growth rate in NO is very low. Other experiments on the effects of growth kinetics show that the growth rate is also a very weak function of time for the samples with an initial oxide of 4 $\mathrm{nm}$. Fig. 1 shows the $\mathrm{Si}, \mathrm{O}$, and N XPS distribution profiles for the NO annealed samples, ON1 $\left(5 \mathrm{~min}\right.$ at $\left.1000^{\circ} \mathrm{C}\right)$ and ON2 $\left(5 \mathrm{~min}\right.$ at $\left.1150^{\circ} \mathrm{C}\right)$. The nitrogen concentrations at the dielectric-silicon interface are $3.9 \%$ and $5.0 \%$ for ON1 and ON2, respectively, and drop to about $2 \%$ at the surface of the dielectric films. These nitrogen concentrations are much higher than those reported for annealing in $\mathrm{N}_{2} \mathrm{O}$ ambient: the highest nitrogen concentration we have obtained using $\mathrm{N}_{2} \mathrm{O}$ annealed oxides is around $1.4 \%$ (results not shown here) [15]. It can be seen from Fig. 1 that the nitrogen in NO-annealed samples piles up at the dielectric-silicon interface region; this is different from the case of the dielectrics grown directly in an NO ambient, where the nitrogen is distributed uniformly through the dielectric layer at about 5.3\% [14], [15], [17]. The nitrogen profile of the NO-annealed samples is attributed to the reaction of the nitrogen from NO with the defect centers in the suboxide layer of the initial thermal oxide.

Fig. 2 shows the $\mathrm{C}-\mathrm{V}$ and the I-V characteristics of aluminum gate MOS capacitors (gate area $=0.01 \mathrm{~cm}^{2}$ made with the two samples (ON1 and ON2) which were annealed in a nitric oxide ambient at $1000^{\circ} \mathrm{C}$ and $1150^{\circ} \mathrm{C}$, both for $5 \mathrm{~min}$. Characteristics for the $\mathrm{O}_{2}$ grown oxide $\left(950^{\circ} \mathrm{C}\right.$ for $\left.30 \mathrm{~s}\right)$ are also shown for comparison. Fig. 2 shows that there is a kink in the high-frequency $\mathrm{C}-\mathrm{V}$ curve of the initial oxide which is an effect already observed in thermal oxides [18]. Fig. 2 also shows that the annealing in NO removes this kink. The absence of this kink was also observed with the NO-grown samples [15], [17]. These results would indicate that interface defects giving rise to the kink are removed just as effectively

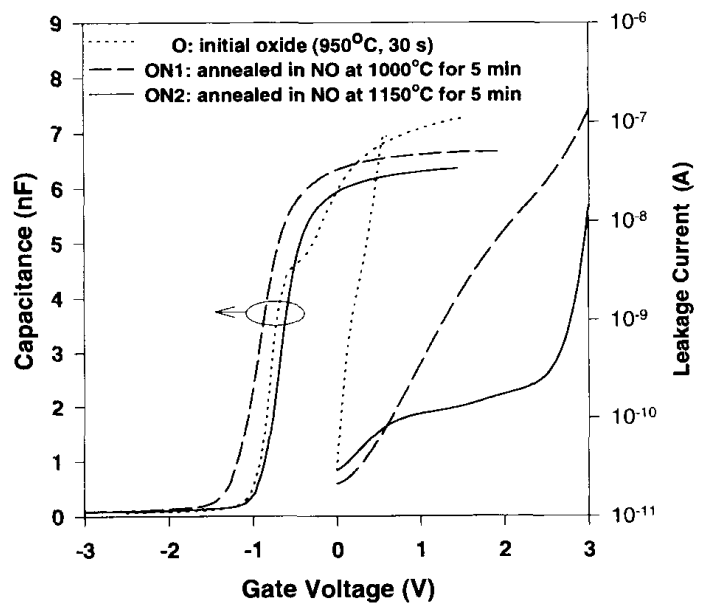

Fig. 2. C-V and I-V characteristic curves for initial oxide $\left(950^{\circ} \mathrm{C}, 30 \mathrm{~s}\right)$ and its $\mathrm{NO}$-annealed sample $\mathrm{ONI}$ (annealed in $\mathrm{NO}$ at $1000^{\circ} \mathrm{C}$ for $5 \mathrm{~min}$.) and $\mathrm{ON} 2$ (annealed in NO at $1150^{\circ} \mathrm{C}$ for $5 \mathrm{~min}$.). The gate area of the MOS capacitors is $0.01 \mathrm{~cm}^{2}$

at $1000^{\circ} \mathrm{C}$ as at $1150^{\circ} \mathrm{C}$ (at least for the $5 \mathrm{~min}$ anneal time). A flat-band voltage shift has been observed when comparing the $\mathrm{ON} 2$ to $\mathrm{ON} 1$ and the control oxide. This shift indicates reduction of a positive trapped charge in the oxide during the annealing process in NO. The leakage current plots in Fig. 2 show a dramatic improvement provided by NO anneal, especially for the sample annealed at $1150^{\circ} \mathrm{C}$. The I-V plots point to the fact that annealing temperature is a very sensitive parameter in the improvement of the quality of the dielectrics. From Figs. 1 and 2, it could be concluded that the quality of the dielectrics is directly proportional to nitrogen concentration in the bulk of the dielectrics. The mid-gap interface state density of the initial oxide was $6.26 \cdot 10^{11} \mathrm{~cm}^{-2} \cdot \mathrm{eV}^{-1}$ as measured using the conductance technique [19]. Annealing in $\mathrm{NO}$ at $1000^{\circ} \mathrm{C}$ and $1150^{\circ} \mathrm{C}$, both for $5 \mathrm{~min}$, reduced the midgap interface state densities to $1.49 \cdot 10^{11} \mathrm{~cm}^{-2} \cdot \mathrm{eV}^{-1}$ and $1.40 \cdot 10^{11} \mathrm{~cm}^{-2} \cdot \mathrm{eV}^{-1}$, respectively, which is a reduction by a factor of about 5 . While the mid-gap interface state density of $1.5 \cdot 10^{11} \mathrm{~cm}^{-2} \cdot \mathrm{eV}^{-1}$ is one order of magnitude higher than the values expected from thicker gate dielectric films used in MOSFET devices, it is two to three times lower than that seen in ultrathin $\mathrm{N}_{2} \mathrm{O}$-grown or annealed oxide. Although the nitrogen concentration in the ON2 sample is higher, the mid-gap interface state densities in $\mathrm{ON} 1$ and $\mathrm{ON} 2$ samples are similar. This indicates that the nitrogen is mostly spent on neutralizing the oxide traps, as indicated by the abovementioned flat-band voltage shift (Fig. 2).

We have also investigated the response of electrical characteristics in response to anneal time at constant anneal temperatures. The MOS capacitors for thermal oxide samples annealed at $1150^{\circ} \mathrm{C}$ for $1 \mathrm{~min}$ and $5 \mathrm{~min}$ were measured. Identical improvements compared to the initial oxide samples were observed for both samples ( 1 and $5 \mathrm{~min}$ of $\mathrm{NO}$ anneal) in both the high frequency $\mathrm{C}-\mathrm{V}$ and the dc leakage current characteristics. Our XPS results show there is no significant nitrogen concentration difference in the NO-annealed oxides 
which were annealed at $1150^{\circ} \mathrm{C}$ for $1 \mathrm{~min}$ and $5 \mathrm{~min}$. These results suggest that the improvement is a reaction rate limited process in the bulk of the dielectric through the incorporation of nitrogen atoms in the dielectric. Overall, we speculate that the nitrogen incorporated reduces the number of dangling bonds in the bulk of the dielectric film, observed as trapped charges, as well as those at the dielectric, which mainly react with silicon dangling bonds at the interface region and the bulk of the film so as to reduce the interface state density and oxide trap density.

The charge-trapping behavior of the NO-annealed oxides (ON1 and $\mathrm{ON} 2$ ) was investigated using a positive gate bias Fowler-Nordheim constant-current stressing of $+5.0 \mu \mathrm{A} / \mathrm{cm}^{2}$ for $300 \mathrm{~s}$. The change in gate voltage was monitored during stress, and $\mathrm{G}-\mathrm{V}$ measurements were performed before and immediately after stressing, to determine the generation of the interface states $\left(\Delta D_{\mathrm{it}}\right)$ resulting from the stress. During the stress, the changes of gate voltage $\left(\Delta V_{\mathrm{g}}\right)$ needed to maintain the constant current were monitored. After the constant current stressing, the $\Delta D_{\mathrm{it}}$ of $\mathrm{ON} 1$ and $\mathrm{ON} 2$ samples were 0.3 and $0.21 \cdot 10^{11} \mathrm{~cm}^{-2} \cdot \mathrm{eV}^{-1}$, respectively. The gate voltage shifts during the constant current stressing were negative for both ON1 and ON2 samples and the shifts saturated after $100 \mathrm{~s}$ stress. The maximum shifts for ON1 and ON2 samples were $-0.11 \mathrm{~V}$ and $-0.13 \mathrm{~V}$, respectively, indicating positive charge buildup during stress. The results shown here indicate that the incorporation of nitrogen can improve the interface endurance against the hot carriers charge-trapping properties.

\section{CONCLUSION}

The characteristics of NO-annealed oxides have been investigated in this letter. The results show that the NO annealing process not only introduces higher nitrogen concentration in the annealed oxides, but also leads to significant improvement in their electrical properties, such as lower intrinsic interface state density, and reduced interface state generation and lower trap generation rate in the bulk of the annealed oxides during electrical stress, while the thickness increase after the NO annealing process is less than $5 \AA$. A significant observation is that the improvement in dc leakage current through the thin $(<5 \mathrm{~nm})$ annealed oxide, and the improvement in its interface characteristics as observed via high frequency $C-V$ and interface state density measurements, respond differently to anneal temperature. We attribute the difference in the response to the incorporation of nitrogen in the bulk of the dielectric and at the interface during annealing.

\section{REFERENCES}

[1] K. Naruke, S. Taguchi, and M. Wada, "Stress induced leakage current limiting to scale down EEPROM tunnel oxide thickness," in IEDM Tech. Dig., 1988, p. 424.

[2] P. Olivo, T. N. Ngyyen, and B. Ricco, "High-field-induced degradation in ultrathin $\mathrm{SiO}_{2}$ films," IEEE Trans. Electron Devices, vol. 35, p. 2259, 1988.

[3] R. Moazzami and C. Hu, "Stress-induced current in this silicon dioxide films," in IEDM Tech. Dig., 1992, p. 92.

[4] T. Ito, T. Nakamura, and H. Ishikawa, "Advantages of thermal nitride and nitroxide gate films in VLSI process," IEEE Trans. Electron Devices, vol. ED-29, p. 498, 1982

[5] T. Hori, H. Iwasaki, Y. Naito, and H. Esaki, "Electrical and physical characteristics of thin nitride oxides prepared by rapid thermal processing," IEEE Trans. Electron Devices, vol. ED-34, p. 2238, 1987.

[6] T. Hori, H. Iwasaki, and K. Tsuji, "Electrical and physical characteristics of ultrathin reoxidized nitride oxides prepared by rapid thermal processing," IEEE Trans. Electron Devices, vol. 36, p. 340, 1989

[7] P. Pan, "Characteristics of thermal $\mathrm{SiO}_{2}$ films during nitridation," J. Appl. Phys., vol. 61, p. 284, 1986.

[8] Z. Liu, H.-J. Wann, P. K. Ko, C. Hu, Y. C. Cheng, "Effects of $\mathrm{N}_{2} \mathrm{O}$ anneal and reoxidation on thermal oxide characteristics," IEEE Electron Device Lett., vol. 13, p. 402, 1992.

[9] H. Fukuda, M. Yasuda, T. Iwabuchi, and S. Ohno, "Novel $\mathrm{N}_{2} \mathrm{O}$ oxynitridation technology for forming high reliable EEPROM tunnel oxide film," IEEE Electron Device Lett., vol. 12, p. 587, 1991.

[10] J. Ahn, W. Ting, and D.-L. Kwong, "Furnace nitridation of thermal $\mathrm{SiO}_{2}$ in pure $\mathrm{N}_{2} \mathrm{O}$ ambient for ULSI MOS applications," IEEE Electron Device Lett., vol. 13, p. 117, 1992.

[11] A. B. Joshi, J. Ahn, and D. L. Kwong, "Oxynitride gate dielectrics for $\mathrm{P}^{\dagger}$-polysilicon gate MOS devices," IEEE Electron Device Lett., vol. 14, p. $560,1993$.

[12] T. Hori, "Nitrided gate-oxide CMOS technology for improved hotcarrier reliability," Microelec. Eng., vol. 22, 1993, p. 245.

[13] G. W. Yoon, A. B. Joshi, J. Kim, and D.-L. Kwong, "MOS characteristics of $\mathrm{NH}_{3}$ nitrided $\mathrm{N}_{2} \mathrm{O}$-grown oxides," IEEE Elecron Device Lett., vol. 14, p. 179, 1993.

[14] Z.-Q. Yao, H. B. Harrison, S. Dimitrijev, Y. T. Yeow, and D. Sweatman, "High quality ultra thin dielectric films grown on silicon in a nitric oxide ambient," Appl. Phys. Lett., vol. 64, p. 3845, 1994.

[15] Z.-Q. Yao, H. B. Harrison, S. Dimitrijev, and Y. T. Yeow, "High quality sub-5 nm dielectric films grown on silicon in a nitric oxide ambient," in Proc. SPIE Conf. in Microelect. Technol. Integ., vol. 2335, p. 265, 1994.

[16] "The electrical properties of sub- $5 \mathrm{~nm}$ oxynitride dielectrics prepared in a nitric oxide ambient using rapid thermal processing," IEEE Electron Device Lett., vol. 15, no. 12, p. 516, 1994.

[17] Ze.-Q. Yao, "The nature and distribution of nitrogen in silicon oxynitride grown on silicon in a nitric oxide ambient," J. Appl. Phys., to be published.

[18] M. Depas, R. L. Van Meirhaeghe, W. H. Lafere, and F. Cardon, "Electrical characteristics of $\mathrm{Al} / \mathrm{SiO}_{2} / n-\mathrm{Si}$ tunnel diodes with an oxide layer growth by rapid thermal oxidation," Solid-State Electronics, vol. 37, p. 433,1994

[19] E. H. Nicollian and J. R. Brews, MOS Physics and Technology. New York: John Wiley, 1982 